\title{
Run for the hills: Italian investors' risk appetite before and during the financial crisis
}

\author{
Andrea Lippi and Simone Rossi \\ Università Cattolica del Sacro Cuore Sede di Piacenza e Cremona, Piacenza, Italy
}

\begin{abstract}
Purpose - This paper sets out to corroborate the existing literature on investors' risk tolerance and to assess how the 2008 financial crisis has affected risk tolerance among Italian investors.

Design/methodology/approach - Based on a unique dataset of real-world portfolio choices made by 1,245 Italian investors over a period of 15 years (from 2003 to 2017), this paper presents two steps of analysis. In step 1 , the whole period 2003-2017 is considered with the aim to integrate and corroborate the existing literature on the topic of risk tolerance, considering a complete economic and financial cycle. Step 2 took 2008 as the pivotal point between pre-crisis (2003-2008) and crisis (2009-2017) with the aim to observe the influence on risk appetite of the economic and financial effects of the crisis.

Findings - The results obtained confirm that men are more risk tolerant than women and older people are less risk-taking than their younger counterparts, although the relationship between age and risk tolerance is not necessarily linear. Moreover, our paper demonstrates that a crisis scenario has an influence on Italian investors' risk tolerance.

Practical implications - Our results are of interest to financial advisors, financial planners, asset managers, psychologists, behavioral researchers and more in general to providers of financial products and services.

Originality/value - The results presented in this paper are relevant and original because they are based on real investors who made real choices concerning their portfolio asset allocations.
\end{abstract}

Keywords Decision making, Risk tolerance, Risk appetite, Financial crisis effects

Paper type Research paper

\section{Introduction}

Individual risk tolerance is a complex psychological concept widely reported in the literature. Its significance lies in the influence of risk-adverse and/or risk-seeking attitudes on decisionmaking processes, with repercussions at social, psychological, ethical and financial levels. Measuring financial risk tolerance is a difficult task due to its multidimensional nature (Trone et al, 1996). Previous research (e.g. Irwin, 1993) has tried to tackle this issue by examining various factors that can influence risk tolerance, such as demographic factors (e.g. age and gender), socioeconomic status, (e.g. income, education, net worth) and family situation (e.g. marital status). Boyd et al. (1994), Levesque and McDougall (1996) and, in particular Xiao et al. (2001) and Jamal and Naser (2002), find that factors such as age, race and net worth affect risktaking attitudes and behaviors. However, the findings of these studies are not always convergent, and the topic of risk tolerance thus remains an interesting area of study.

From a financial perspective, changes in investors' risk tolerance and their determinants are of particular interest to financial advisors and asset managers, as well as to policymakers and suppliers of financial products and services. Indeed, significant changes in risk tolerance can lead to adjustments in asset allocation, a lively portfolio turnover, and modifications in financial planning choices.

(C) Andrea Lippi and Simone Rossi. Published by Emerald Publishing Limited. This article is published under the Creative Commons Attribution (CC BY 4.0) licence. Anyone may reproduce, distribute, translate and create derivative works of this article (for both commercial and non-commercial purposes), subject to full attribution to the original publication and authors. The full terms of this licence may be seen at http://creativecommons.org/licences/by/4.0/legalcode

Italian investors' risk appetite

Received 14 February 2020 Revised 29 March 2020 2 May 2020

Accepted 11 May 2020

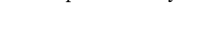

(1)

(1)

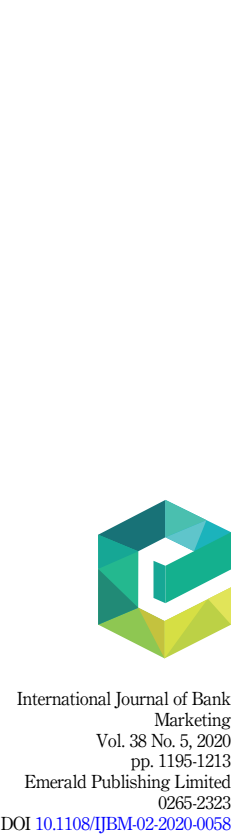


IJBM 38,5

1196

Investors' risk appetite determinants are important to: (1) supply financial advice more consistent with the real level of risk acceptable by each investor, as we believe this is very important especially as regards fintech financial advisory; and (2) enable supervisors to check the appropriate level of risk assumed by each investor through his/her portfolio asset allocation. Indeed, considering the literature on investor's risk tolerance, supervisors may be able to determine some clusters of risks attributable to individuals according to their sociodemographic characteristics. This makes it possible to verify whether the level of risk taken by investors through asset allocation is consistent with the cluster of risk they belong to; (3) identify investment products which consider investors' reactions when the macroeconomic context changes; and (4) enable financial advisors to make a careful selection of investment products for their clients considering their socioeconomic characteristics.

Furthermore, drastic variations in risk tolerance can generate an excess or reduced demand for specific categories of financial and insurance products, generating significant consequences on the supply side. As a consequence, these behaviors are likely to influence perceived levels of customer satisfaction as well as financial intermediaries' overall profitability.

From this point of view, the Lehman Brothers affair of 2008 represents a turning point because of its impact on decisions made by consumers, investors, and also institutions and regulators. Following the outbreak of the crisis, a long chain of events of a macroeconomic and financial nature took place all over the world. The collapse of financial markets, and in particular the stock market, was associated with a significant reduction in house prices, which in some countries represent a significant share of household wealth. In Italy, the trend of GDP has slowed down drastically: the variation observed between 2008 and 2009 was negative by more than $5 \%$ points, the worst since 1971 . The unemployment rate has increased, while the country's banking system has been put to the test due to the bankruptcy of some important financial intermediaries. The rise in the BTP-Bund spread led to a significant reduction in the price of Italian government bonds and thus to a deterioration in the portfolios of many households and institutional investors, including banks. It is not surprising that after these severe macroeconomic and microeconomic imbalances, investors have drastically changed their asset allocation decisions, usually in the form of a massive flight-to-quality tendency, widespread in the financial system. However, there is still a lack of studies devoted to the impact of the recent economic and financial crisis on investor risk tolerance modification.

Based on a unique dataset that monitors portfolio choices made by 1,245 Italian investors over a period of 15 years (from 2003 to 2017), this paper intends to contribute to fill that gap. More specifically, the aim of our study is twofold: on the one hand, the number of variables observed in this research allows us to corroborate the existing literature on the determinants of risk tolerance through the cycle; on the other, the length of the time period observed allows us to assess whether and how the 2008 crisis has affected investors' risk tolerance. The results presented in this paper are particularly relevant because they are based on real investors who made real choices concerning their portfolio allocations. Therefore, they are of interest to all those who deal with financial planning in any way. Moreover, this research introduces and tests several hypotheses about the risk-seeking attitudes of investors during severe economic downturns, filling a gap in existing literature.

The remainder of this paper is organized as follows. In Section 2 we present the related literature, and in Section 3 we introduce our sample. In Section 4 we present our methodology and results, while in Section 5 we discuss the obtained results; Section 6 concludes.

\section{Conceptual frameworks, previous research and hypotheses}

Financial risk tolerance has been studied from different perspectives by psychologists, sociologists and economists. More specifically, it has been defined as a psychological component of decision making under financial uncertainty, a situation in which individuals evaluate the desirability of possible outcomes and their likelihood of occurring (Kahneman 
and Tversky, 1979). According to Trone et al. (1996), measuring a person's financial risk tolerance is difficult because being a multidimensional attitude, it is an elusive concept that appears to be influenced by a number of predisposing factors. Bell and Bell (1993) and Tigges et al. (2000) test factors related to risk-tolerance attitudes. Wong and Carducci (1991) find a positive relationship between certain biopsychosocial factors (i.e. sensation-seeking and aggressiveness) and risk-tolerance attitudes. Zuckerman (1979), Horvath and Zuckerman (1993), and Shelbecker and Roszkowski (1993) have described the role of other psychosocial characteristics (e.g. self-esteem and personality) as possible factors that have an impact on a person's risk-tolerance attitude.

Irwin (1993) highlights the existence of different predisposing factors that influence risktolerance attitudes. The author classifies these predisposing factors into two categories: environmental and biopsychosocial ones. Examples of environmental factors include socioeconomic status (e.g. income, education, net worth), family situation (e.g. marital status), and social transition. Biopsychosocial factors include characteristics such as age, gender, ethnicity, personality traits and birth order.

The relationship between gender difference and risk tolerance has long been considered in the literature. A plethora of studies (e.g. Burton, 1995; Graham et al., 2002) based on different samples and methodologies demonstrate that men tend to be more risk tolerant than women. In particular, Guiso et al. (1996) use the 1989 Bank of Italy Survey of Households income and wealth while Pålsson (1996) uses a Swedish cross-sectional dataset. Many studies are based on the Survey of Consumer Finances (SCF). Sung and Hanna (1996) consider only working respondents aged between 16 and 70 included in 1992 SCF; the 1995 SCF and the $1989 \mathrm{SCF}$ are considered in the research of Embrey and Fox (1997) and Jianakoplos and Bernasek (1998), respectively. Yao et al. (2004) use a logit regression to test changes in risk tolerance considering six SCF cross-sectional dataset from 1983 to 2001. In their studies, Morse (1998), Grable (2000), Bernasek and Shwiff (2001) and Hartog et al. (2002) use some questionnaires while Powell and Ansic (1997) use some computerized laboratory experiments. Hariharan et al. (2000) consider survey data reported in 1992 Health and Retirement Survey concerning individuals from 51 to 61 years old. Gilliam et al. (2010) use a sample of respondents to the FinaMetrica risk tolerance questionnaire US residents born between 1946 through 1964 to confirm that men tend to be more risk-tolerant than women. Sung and Hanna (1996) and Huston et al. (1997) find that gender, marital status, ethnicity and education predict risk tolerance. However, Grable and Joo (1997), Hanna et al. (2001) and Hari et al. (2018) find that gender is not significant in predicting financial risk tolerance.

With regards to marital status, Baker and Haslem (1974) and Cohn et al. (1975) argue that married individuals tend to be less risk-taking than singles. Roszkowski et al. (1993) find that single investors are more risk tolerant than married people and the same conclusion is supported by the studies carried out by Guiso et al. (1996), Sung and Hanna (1996), Hinz et al. (1997), Gutter et al. (1999), and in more recent years by Hartog et al. (2002), Grable and Joo (2004), Hallahan et al. (2004), Yao et al. (2004) and Fan and Xiao (2006). The main justification for this result is that single individuals do not bear the same responsibilities as those that are married, and thus single individuals are willing to accept more financial risk. When gender and marital status are considered together, Jianakoplos and Bernasek (1998) and Bernasek and Shwiff (2001) find that single men tend to be more risk tolerant than single women. Sunden and Surette (1998) conclude that single women and married men are less risk tolerant compared with single men. According to Chaulk et al. (2003), married individuals tend to be less financially risk-tolerant because of a greater need for wealth protection. However, McInish (1982), Masters (1989), and Haliassos and Bertaut (1995) argue that no significant relationship is identifiable between marital status and risk tolerance. 
IJBM

38,5
Bearing in mind this literature review, we formulate two starting hypotheses:

Focusing on gender, we expect that:

H1. Men tend to be more risk tolerant than women.

H1a. Men remain more risk tolerant than women during troubled periods.

A plethora of studies argue that financial risk tolerance decreases with age (Wallach and Kogan, 1961; McInish, 1982; Morin and Suarez, 1983; Dahlbäck, 1991; Bakshi and Chen, 1994; Schooley and Worden, 1996; Donkers and Van Soest, 1999; Fan and Xiao, 2006; Faff et al., 2009). On the contrary, Xiao and Anderson (1997) and Wang and Hanna (1997) find that financial risk tolerance increases with age. However, there are also many studies which have found no relationship between age and risk tolerance (Cutler, 1995; Grable and Joo, 1997; Grable and Lytton, 1999; Hariharan et al., 2000; Hanna et al., 2001; Gollier; Zeckhauser, 2002). Using a sample of 15,916 Australian respondents to the survey for the FinaMetrica Personal Financial Profiling system over the period May 1999-February 2002, Faff et al. (2009) point out that the relationship between age and risk tolerance is not necessarily linear. This result confirms the studies of Riley and Chow (1992), Bajtelsmit and VanDerhei (1997), Hallahan et al. (2004) and Grable et al. (2006).

Our hypotheses are:

H2. Risk tolerance decreases with age;

H2a. During a crisis, risk tolerance decreases more strongly with age.

According to Baker and Haslem (1974), Haliassos and Bertaut (1995) and Sung and Hanna (1996), the higher an investor's education level, the greater his/her capacity to evaluate investment risk, thus leading to a higher risk tolerance. Meyer et al. (1961), Quattlebaum (1988), Masters (1989) and Haliassos and Bertaut (1995) find that increasing levels of risk tolerance have also been associated with being employed in a professional occupation.

Hawley and Fujii (1993-1994), Sung and Hanna (1996), Kennickell et al. (1997) and Grable and Lytton (1999) argue that certain demographic and socioeconomic environmental characteristics (e.g. income) can predict risk tolerance. In this field of research, the studies by Friedman (1974), Cohn et al. (1975), Schooley and Worden (1996), Shaw (1996), Grable and Lytton (1999), Grable (2000), Bernheim et al. (2001), Chaulk et al. (2003), Yook and Everett (2003), Chang et al. (2004), Grable and Joo (2004), Hallahan et al. (2004), Yao et al. (2004) and Fan and Xiao (2006) find a higher financial risk tolerance among people in high income/ wealth categories. In particular, Hallahan et al. (2004) find a positive relationship between the level of risk tolerance and income, wealth and education, suggesting that financial risk tolerance could be a function of income and wealth rather than education. Many studies (Baker and Haslem, 1974; Cicchetti; Dubin, 1994; Cohn et al., 1975; Riley and Chow, 1992; Zhong and Xiao, 1995; Schooley and Worden, 1996; Shaw, 1996; Grable, 2000; Grable and Joo, $2000,2004)$ find that increased levels of income and educational attainment are associated with increased levels of risk tolerance. We argue that people characterized by a greater level of education should make better use of publicly available information. During "normal" times, they are expected to show higher risk tolerance, since they want to take benefits from the virtuous risk-return profile of stock markets. However, during a financial downturn, they will adjust their portfolio according to the new information: they can both reduce or increase the riskiness of their investments using a tactical asset allocation approach. Moreover, people with a lower level of income can feel a greater pressure on the personal financial balance when a crisis period occurs, leading to more conservative asset allocation.

We formulate several hypotheses on these topics.

H3. The higher the education level, the higher the risk tolerance; 
H3a. During a crisis period, the relationship between education level and risk tolerance is not significant;

H4. The higher the level of income, the higher the risk tolerance;

investors' risk

appetite

H4a. During a crisis, the positive relationship between income and risk tolerance is stronger;

H5. The higher the level of wealth, the higher the risk appetite;

H5a. During a crisis period, the relationship between the level of wealth and risk appetite remains positive.

The preceding hypotheses represent the first attempt to provide a rationale for the (expected) different effect of traditional determinants of risk governance during a crisis period. In fact, there are few studies in the literature that consider the relationship between individual risk tolerance and financial crises. These papers are usually based on data collected through surveys and/or specific questionnaires (Bateman et al., 2011; Hoffmann et al., 2013; Gerrans et al., 2015; Schooley and Worden, 2016), and they are characterized by briefer time-spans examined (2007 and 2008 in the case of the study by Bateman et al., 2011; from 2007 to 2009 in the research by Schooley and Worden, 2016, 2008-2009 in Hoffman et al., 2013; from January 2001 to July 2009 in Gerrans et al., 2015).

Besides providing detailed hypotheses on the different effect of traditional determinants of risk governance before and during a crisis period, our research differs from the studies cited above in two fundamental aspects: the time period analyzed, which covers 15 years (from 2003 to 2017), and the nature of our data, which are taken from real-world investors and therefore represent implemented behaviors by individuals in the management of their investment portfolios.

\section{Sample description}

The data used in this research were taken from the "Italian open-ended Mutual funds shareholders registry" provided by Assogestioni (the association of asset management firms operating in Italy). This unique dataset contains information about the individual owners of mutual fund shares in Italy since 2003: these include gender, age, education, marital status and portfolio composition items.

Since the data are confidential, in this registry shareholders are coded randomly. However, each code remains constant over time for a specific individual, allowing us to track his/her features and choices for the whole time-span under consideration. Data restrictions were necessary to filter outliers and manage missing data. In particular, we excluded from the sample individuals with a net worth invested in mutual funds lower than $€ 15,000$, those with an age outside the 18-90 interval, and those with missing data in any of our variables of interest. This allowed us to work with a strongly balanced panel of data, including 1,245 individuals observed over a period of 15 years (from 2003 to 2017). Moreover, some variables have been provided in a pre-calculated form. The dataset specifies the portfolio composition for each investor per year. Assogestioni chose a $70 \%$ threshold as the trigger for attributing a specific portfolio classification. We recoded this information in three clusters of risk-taking; specifically, if the portfolio held by the individual comprises at least $70 \%$ monetary or bond products, a low risk tolerance is assigned; vice versa, if the portfolio is made up of at least $70 \%$ equity products, a high risk-appetite is attributed. In all other cases, a medium tolerance to risk is assigned. According to these categories, our dependent variable, risk tolerance, assumed a value equal to 0 in the case of a low risk tolerance, 1 in the case of medium risk tolerance, and 2 in the case of high risk-tolerance. Moreover, the investors' level of wealth may 
IJBM

38,5

1200

be grouped into three clusters: up to 99,999 euros, from 100,000 euros to 499,999 euros, and over 500,000 euros. The number of individuals in each cluster $(1.146,14.686$, and 2.843 respectively) is consistent with the Banca d'Italia report titled "The wealth of Italian families."

Table 1 shows the variables used in this study. For each variable, we provide a description and our expectation as to its risk-tolerance influence, following the prevalent literature on the topic.

We divided individuals into those living in the north and in the center-south of Italy. Our expectation was that residents in the north of Italy are more risk-taking than others: there is clear and long-standing evidence that the north and south of Italy are characterized by great differences in per-capita GDP, net wealth and financial portfolio composition [1].

Table 2 shows some descriptive statistics of the sample and highlights the specific features of the panel of available data.

As shown in Table 2, most of the individuals in the sample live in northern Italy (80.20\%). The majority of the individuals are married men (legally or defacto, $60.46 \%$ ), followed by unmarried men (single or widowed, 16.73\%), unmarried women (single or widowed, $11.92 \%$ ), and married women (legally or defacto, 10.89\%). The average age in our sample is about 57

\begin{tabular}{|c|c|c|}
\hline Variable & Description & $\begin{array}{l}\text { Expected } \\
\text { sign }\end{array}$ \\
\hline $\begin{array}{l}\text { Dependent } \\
\text { risk_appetite }\end{array}$ & $\begin{array}{l}\text { This indicates the level of risk taken by each investor year by year } \\
\text { according to his/her portfolio composition. It is an ordinal variable which } \\
\text { considers three categories: } 0 \text { indicates low risk tolerance; } 1 \text { indicates } \\
\text { medium risk tolerance; } 2 \text { indicates high risk tolerance }\end{array}$ & \\
\hline \multicolumn{3}{|l|}{ Independent } \\
\hline north & Dummy variable: 1 if the individual lives in the north of Italy & + \\
\hline center-south & $\begin{array}{l}\text { Dummy variable: } 1 \text { if the individual lives in the center or in the south of } \\
\text { Italy }\end{array}$ & - \\
\hline unmarried_male & $\begin{array}{l}\text { Dummy variable: } 1 \text { if the individual is a single, divorced, separated or } \\
\text { widowed male; } 0 \text { otherwise }\end{array}$ & + \\
\hline unmarried_female & $\begin{array}{l}\text { Dummy variable: } 1 \text { if the individual is a single, divorced, separated or } \\
\text { widowed female; } 0 \text { otherwise }\end{array}$ & - \\
\hline married_male & $\begin{array}{l}\text { Dummy variable: } 1 \text { if the individual is a married male (legally or defacto); } \\
0 \text { otherwise }\end{array}$ & $+/-$ \\
\hline married_female & $\begin{array}{l}\text { Dummy variable: } 1 \text { if the individual is a married female (legally or } \\
\text { defacto); } 0 \text { otherwise }\end{array}$ & $+/-$ \\
\hline age & Age of each investor & - \\
\hline age $^{2}$ & Squared value of the age of each investor & \\
\hline low_edu & $\begin{array}{l}\text { Dummy Variable: } 1 \text { if the individual has no education or if he/she did not } \\
\text { complete high school (low level of education) }\end{array}$ & - \\
\hline mid_edu & $\begin{array}{l}\text { Dummy Variable: } 1 \text { if the individual completed high school (medium level } \\
\text { of education) }\end{array}$ & $+/-$ \\
\hline high_edu & $\begin{array}{l}\text { Dummy Variable: } 1 \text { if the individual has a degree or equivalent (high level } \\
\text { of education) }\end{array}$ & + \\
\hline self-employed & Dummy Variable: 1 if the individual is self-employed & + \\
\hline employed & Dummy Variable: 1 if the individual is salaried & $+1-$ \\
\hline retired & Dummy Variable: 1 if the individual is retired & - \\
\hline low_wealth & Dummy variable: 1 if the individual' level of wealth is up to 99,999 euros & - \\
\hline mid_wealth & $\begin{array}{l}\text { Dummy variable: } 1 \text { if the individual' level of wealth is from } 100,000 \text { euros } \\
\text { to } 500,000 \text { euros }\end{array}$ & $+1-$ \\
\hline high_wealth & Dummy variable: 1 if the individual's level of wealth is over 500,000 euros & + \\
\hline $2003,2004, \ldots$ & Time dummies from 2003 to 2017 & $+1-$ \\
\hline
\end{tabular}

Table 1.

The variables used in the analysis
This indicates the level of risk taken by each investor year by year according to his/her portfolio composition. It is an ordinal variable which considers three categories: 0 indicates low risk tolerance; 1 indicates

Dummy variable: 1 if the individual lives in the north of Italy

Dummy variable: 1 if the individual lives in the center or in the south of

Italy widowed male; 0 otherwise widowed female; 0 otherwise

0 otherwise

defacto); 0 otherwise

Squared value of the age of each investor

complete high school (low level of education)

Dummy Variable: 1 if the individual completed high school (medium level of education)

Dummy Variable: 1 if the individual is salaried

Dummy Variable: 1 if the individual is retired to 500,000 euros

Time dummies from 2003 to 2017

Expected 


\begin{tabular}{|c|c|c|c|c|c|}
\hline \multirow{3}{*}{$\frac{\text { Variable type }}{\text { Dependent variable }}$} & \multicolumn{2}{|l|}{ Variable } & \multirow{3}{*}{$\frac{\text { Mean }}{1.0293}$} & SD & \multirow{3}{*}{$\begin{array}{r}\text { Italian } \\
\text { investors' risk } \\
\text { appetite }\end{array}$} \\
\hline & risk_appetite & Overall & & 0.6840 & \\
\hline & & Between & & 0.4873 & \\
\hline \multirow{48}{*}{ Independent variables } & north & Oyerall & 08020 & 0.48082 & \\
\hline & & Between & 0.0020 & 0.3984 & \\
\hline & & Within & & 0.0141 & 1201 \\
\hline & center-south & Overall & 0.1980 & 0.3985 & \\
\hline & & Between & & 0.3984 & \\
\hline & & Within & & 0.014 & \\
\hline & unmarried_male & Overall & 0.1673 & 0.3732 & \\
\hline & & Between & & 0.3506 & \\
\hline & & Within & & 0.1284 & \\
\hline & unmarried_female & Overall & 0.1192 & 0.3240 & \\
\hline & & Between & & 0.3133 & \\
\hline & & Within & & 0.0833 & \\
\hline & married_male & Overall & 0.6046 & 0.4889 & \\
\hline & & Between & & 0.4720 & \\
\hline & & Within & & 0.1284 & \\
\hline & married_female & Overall & 0.1089 & 0.3115 & \\
\hline & & Between & & 0.3003 & \\
\hline & & Within & & 0.0833 & \\
\hline & age & Overall & 56.975 & 12.4759 & \\
\hline & & Between & & 11.8440 & \\
\hline & & Within & & 4.4941 & \\
\hline & low_edu & Overall & 0.3361 & 0.4724 & \\
\hline & & Between & & 0.4543 & \\
\hline & & Within & & 0.1301 & \\
\hline & mid_edu & Overall & 0.4533 & 0.4978 & \\
\hline & & Between & & 0.4739 & \\
\hline & & Within & & 0.1531 & \\
\hline & high_edu & Overall & 0.2106 & 0.4077 & \\
\hline & & Between & & 0.3991 & \\
\hline & & Within & & 0.0844 & \\
\hline & self-employed & Overall & 0.3391 & 0.4734 & \\
\hline & & Between & & 0.4116 & \\
\hline & & Within & & 0.2343 & \\
\hline & employed & Overall & 0.3942 & 0.4887 & \\
\hline & & Between & & 0.4166 & \\
\hline & & Within & & 0.2557 & \\
\hline & retired & Overall & 0.2667 & 0.4423 & \\
\hline & & Between & & 0.3772 & \\
\hline & & Within & & 0.2311 & \\
\hline & low_wealth & Overall & 0.6137 & 0.2400 & \\
\hline & & Between & & 0.1333 & \\
\hline & & Within & & 0.1996 & \\
\hline & mid_wealth & Overall & 0.7864 & 0.4099 & \\
\hline & & Between & & 0.2705 & \\
\hline & & Within & & 0.3080 & Summary of variables \\
\hline & high_wealth & Overall & 0.1522 & 0.3593 & shown in the dataset \\
\hline & & Between & & 0.2650 & $(n=1,245 ; N=18,675$ \\
\hline & & Within & & 0.2426 & years: 2003-2017) \\
\hline
\end{tabular}

years. With reference to levels of education, 33.61\% are investors with a low level of education, that is to say, individuals who have no education or did not complete high school; 
IJBM

38,5

1202

$45.33 \%$ of individuals completed high school, while $21.06 \%$ have a degree or equivalent. Our sample consists of $33.91 \%$ self-employed workers, $39.42 \%$ employees, and $26.67 \%$ retired workers. Due to the long period of time covered by our sample, as shown in Table 2 , status changes can occur within the categories described above.

Graph 1 shows the dynamics of the dependent variable (risk appetite) over the period of time examined.

First of all, it is clearly observable that portfolios mainly exposed to the most risky component (i.e. equity products) have disappeared since 2009, a year after the beginning of the global financial crisis in 2008. The change in risk appetite is evident and striking: individuals literally flee from the most aggressive investments. Second, it is possible to observe that among Italian investors, the risk profile of mutual fund portfolios is generally moderate. In line with this view, Table 3 suggests that risk tolerance shown by Italian investors is deeply influenced by the macroeconomic context. This result is confirmed and justified by the literature.

Indeed, according to Kahneman and Riepe (1998), investors tend to be overconfident in bull markets but exhibit myopic loss aversion (Benartzi and Thaler, 1995). This combination explains swings in portfolio choices before and after crises, as highlighted in Table 3. In fact, the reduction in the number of investors holding high-risk portfolios is dramatic before 2008 and after 2008 (52.93 vs 5.95\%); nevertheless, it is very interesting to observe that after 2008 , the majority of investors shift to a medium-risk portfolio level $(74.11 \%)$.

\section{Methodology and analysis}

The analysis described in this paper was carried out in two steps. In Step 1 we examined the sample over the whole time period under consideration (2003-2017). The aim of this step was to integrate and corroborate the existing literature on the topic of risk tolerance, considering a

Graph 1.

Dynamic of risk appetite over time (2003-2017)

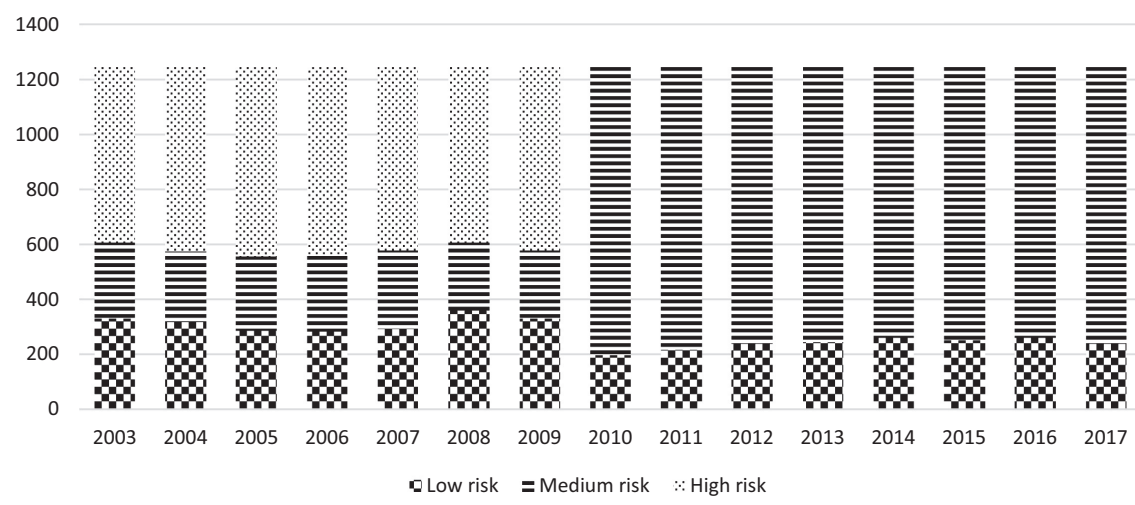

Table 3.

Investor distribution as regards risk tolerance

\begin{tabular}{|c|c|c|c|c|}
\hline Risk tolerance & $\begin{array}{c}\text { Number of investors } \\
\text { 2003-2008 }\end{array}$ & $\%$ & $\begin{array}{c}\text { Number of investors } \\
\text { 2009-2017 }\end{array}$ & $\%$ \\
\hline Low & 1,869 & 25.02 & 2,234 & 19.94 \\
\hline Medium & 1,618 & 21.66 & 8,304 & 74.11 \\
\hline High & 3,983 & 53.32 & 667 & 5.95 \\
\hline Total & 7,470 & 100 & 11,205 & 100 \\
\hline
\end{tabular}


complete economic and financial cycle. Step 2 took 2008 as the pivotal point between the precrisis and the crisis periods. We thus divided the dataset into two subsamples: pre-crisis (2003-2008) and crisis (2009-2017). In this way, we aimed to observe the influence on risk appetite of the economic and financial effects of the crisis.

Step 1 - Overall analysis

In this step, we considered 18,675 observations over a period of 15 years, from 2003 to 2017. Since risk appetite is a categorical variable ranging from 0 to 2 , a panel ordered logistic regression was used. The estimated equation is as follows:

$$
\begin{aligned}
& \text { risk_appetite }=c+\propto_{1} \sum_{i=1}^{2} \operatorname{area}_{-} i+\propto_{2} \sum_{j=1}^{4} \text { maritalstatus }_{-} j+\propto_{3} \text { age }+\propto_{4} \text { age }^{2} \\
& +\propto_{5} \sum_{z=1}^{3} z_{-} \mathrm{edu}+\boldsymbol{\alpha}_{6} \sum_{k=1}^{3} \mathrm{job}_{-} k+\propto_{7} \sum_{w=1}^{3} w_{-} \text {wealth }+\propto_{8} \sum_{t=1}^{15} T_{t}
\end{aligned}
$$

where:

(1) area $i$ is the codification for northern (north), central and southern (center-south);

(2) maritalstatus_j indicates if the individual is a single male (single_male), single female (single_female), married male (married_male), or married female (married_female);

(3) age indicates the age of each investor, and age $\mathrm{e}^{2}$ is its squared value;

(4) $z$ _edu indicates the education level achieved by the investor, specifically low_edu indicating a low level of education, mid_edu a medium level of education, and high_edu a high level of education;

(5) job_ $k$ indicates if the individual is self-employed, employed or retired;

(6) wealth_w indicates the investor's level of wealth, specifically low_wealth indicating a level of wealth up to 99,999 euros (retail investors), mid_wealth a level between 100,000 euros and 499,999 euros (usually linked to affluent investors), and high_wealth a level over 500,000 euros (typical of private investors);

(7) $T$ indicates time dummies from 2003 to 2017.

The results obtained are shown in Table 4.

Outcomes suggest that investors living in northern Italy are more risk tolerant than those in central and southern Italy.

Males are more risk-taking than females and this result confirms H1; based on our results, we state that gender (male or female) prevails over marital status. More specifically, this is confirmed for both unmarried men $(\phi<0.01)$ and for those who are married $(\phi<0.05)$. The results obtained therefore confirm conclusions expressed in the prevailing literature, i.e. that men are more risk tolerant than women, but do not support the conclusions of some researchers (e.g. Chaulk et al., 2003) who claim that married men and single women are less risk tolerant than single men.

In accordance with the prevailing literature (e.g. among others Yao et al., 2004; Fan and Xiao, 2006), the result obtained with reference to the age variable confirms H2: there is an inverse relationship between increasing age and risk tolerance. However, the significance and sign of the variable "age-squared" shows that the relationship between age and risk tolerance is not necessarily linear, as was argued by Hallahan et al. (2004), Grable et al. (2006), and Faff et al. (2009), among others. 
IJBM
38,5

north

$0.550^{*}$

unmarried_male

(0.319)

unmarried_female

$1.005^{* * * *}$

(0.380)

$-0.600$

(0.447)

married_male

$0.644^{* *}$

1204

age

$-0.474 * * *$

$(0.0665)$

age $^{2}$

low_edu

(0.0005)

high_edu

0.216

(0.279)

$-0.0096$

self-employed

(0.230)

$0.335 *$

(0.181)

retired

-0.490 **

(0.231)

low_wealth

$1.028 * * *$

mid_wealth

(0.241)

$0.819 * * *$

(0.159)

2003

$1.769 * * *$

(0.194)

2004

$2.085^{* * * *}$

(0.189)

2005

$2.422 * * *$

(0.181)

2006

2.470 ****

(0.175)

2007

2.420 ***

(0.169)

2008

$1.969 * * *$

2009

(0.167)

$2.319 * * *$

(0.163)

2010

0.023

(0.086)

2011

$-0.0468$

2012

(0.0859)

$-0.102$

(0.078)

2013

$-0.0797$

(0.0720)

2014

$-0.126^{* *}$

(0.0597)

2015

$-0.0661$

(0.0500)

2016

$-0.115^{* *}$

Observations

(0.0431)

Table 4.

Number of individuals

18,675

Note(s): Ordered logistic regression. Dependent variable: Risk tolerance. Time span under scrutiny: 15 years

Panel regression analysis on the whole (2003-2017). Robust standard errors in parentheses. Significance codes: ***indicate statistical significance at $1 \%$,**at $5 \%$ and *at $10 \%$ 
The level of investor education turns out as not being significant in our analysis. This result seems to corroborate the study by Hallahan et al. (2004) according to which individuals' level of risk tolerance does not depend on their level of education. Thus, H3 is rejected.

The self-employed appear to be more risk taking than employees while retired people appear to be less risk-taking ( $p<0.10$ and $p<0.05$ respectively). This result confirms $\mathrm{H} 4$ and supports other studies on this topic (e.g. Masters, 1989; Halaissos and Bertant, 1995).

H5 is not completely supported by the obtained results; indeed, investors seem to be risk seeking independently of their level of wealth.

The values and significance of the time dummies highlight the fact that from 2003 to 2009 the level of risk appetite was positive and strongly significant $(p<0.01)$, while after 2009 significance disappeared.

Step 2 - Analysis of risk appetite before and after the financial crisis (year 2008)

The analysis carried out in Step 2 is intended to demonstrate the consequences on Italian investors' risk appetite of the financial crisis that began in 2008. For this reason, the sample was divided into two subsamples: the first covering the years from 2003 to 2008 (included) and the second covering the years from 2009 to 2017. Equation (1) is then replicated, including a set of time dummies consistent with the time span considered in each estimation. The results obtained are shown in Table 5.

\begin{tabular}{|c|c|c|c|}
\hline \multicolumn{2}{|l|}{ Subsample 2003-2008 } & \multicolumn{2}{|l|}{ Subsample 2009-2017 } \\
\hline \multirow[t]{2}{*}{ north } & $1.534 * * *$ & \multirow[t]{2}{*}{ north } & $0.642^{* *}$ \\
\hline & $(0.326)$ & & $(0.257)$ \\
\hline \multirow[t]{2}{*}{ unmarried_male } & $3.924^{* * * *}$ & \multirow[t]{2}{*}{ unmarried_male } & $0.821^{* * *}$ \\
\hline & $(0.682)$ & & $(0.357)$ \\
\hline \multirow[t]{2}{*}{ unmarried_female } & -0.619 & \multirow[t]{2}{*}{ unmarried_female } & -0.360 \\
\hline & $(0.493)$ & & (0.386) \\
\hline \multirow[t]{2}{*}{ married_male } & $4.240 * * *$ & \multirow[t]{2}{*}{ married_male } & $0.521 *$ \\
\hline & $(0.528)$ & & $(0.312)$ \\
\hline \multirow[t]{2}{*}{ age } & -0.151 & \multirow[t]{2}{*}{ age } & $-0.213^{* * *}$ \\
\hline & (0.137) & & $(0.0774)$ \\
\hline \multirow[t]{2}{*}{ age $^{2}$} & -0.0011 & \multirow[t]{2}{*}{$\operatorname{age}^{2}$} & $0.0018^{* * * *}$ \\
\hline & $(0.0013)$ & & $(0.0006)$ \\
\hline \multirow[t]{2}{*}{ low_edu } & -0.161 & \multirow[t]{2}{*}{ low_edu } & 0.0410 \\
\hline & $(0.305)$ & & (0.218) \\
\hline \multirow[t]{2}{*}{ high_edu } & $1.856 * * *$ & \multirow[t]{2}{*}{ high_edu } & 0.245 \\
\hline & $(0.382)$ & & $(0.218)$ \\
\hline \multirow[t]{2}{*}{ self-employed } & 0.0974 & \multirow[t]{2}{*}{ self-employed } & $0.494 * *$ \\
\hline & (0.282) & & $(0.198)$ \\
\hline \multirow[t]{2}{*}{ retired } & -0.522 & \multirow[t]{2}{*}{ retired } & $-0.534 * * *$ \\
\hline & $(0.384)$ & & $(0.259)$ \\
\hline \multirow[t]{2}{*}{ low_wealth } & $2.840 * * *$ & \multirow[t]{2}{*}{ low_wealth } & 0.312 \\
\hline & $(0.492)$ & & $(0.343)$ \\
\hline \multirow[t]{2}{*}{ mid_wealth } & $2.223^{* * *}$ & \multirow[t]{2}{*}{ mid_wealth } & $0.621 * * *$ \\
\hline & (0.331) & & $(0.192)$ \\
\hline Time dummies & (YES) & Time dummies & (YES) \\
\hline Observations & 7,470 & Observations & 11,205 \\
\hline Number of individuals & 1,245 & Number of individuals & 1,245 \\
\hline
\end{tabular}

Note(s): Ordered logistic regression. Dependent variable: Risk tolerance. Time dummies included. Robust standard errors in parentheses. Significance codes: ***indicate statistical significance at $1 \%$, ** at $5 \%$ and *at $10 \%$

\section{Italian investors' risk appetite}

1205

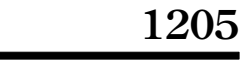

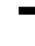


IJBM

38,5

1206

Outcomes show that residents in northern Italy were more risk tolerant until 2009 and continued to be so even after 2008 compared to those living in the center-south of Italy.

It is interesting to note that unmarried men continue to be risk-takers in both subsamples (2003-2008 and 2009-2017), and the same is confirmed for married men. Between the first and second period the significance declined, as did the magnitude of the coefficients: this shows that the crisis also had an impact on risk tolerance among males. However, H1a is confirmed: in general, men tend to be more risk tolerant than women both in a positive and in a negative scenario, but the advent of a crisis can flatten the dissimilarities between different marital status.

From 2003 to 2008, in a period of generalized macroeconomic growth, the age variable does not appear to be significant; from 2009, on the other hand, we observe a negative and significant relationship between age and risk appetite, although it is not necessarily linear. Hence, H2a is confirmed in the case of a negative scenario: macroeconomic context influences the investors' decision making process.

Until 2008, investors with a high level of education were more risk tolerant than those with a school-leaving diploma, confirming the literature on the topic (e.g. Baker and Haslem, 1974; Haliassos and Bertant, 1995; Sung and Hanna, 1996). However, since 2009 the level of education has no longer been significant. This result could be an expression of a flattening behavior caused by the crisis: thus H3a is confirmed.

Until 2008, working status was not significant; since 2009, in contrast, retired people have been less risk tolerant than the employees while the self-employed, on the contrary, are more risk tolerant. For this reason also H4a is confirmed.

Before 2008, investors seem to be risk taking independently of their level of wealth; after $2008 \mathrm{H} 5 \mathrm{a}$ is rejected. In fact, in the case of a negative macroeconomic context wealthier people tend to be less risk tolerant than affluent investors, while the coefficient associated to retail investors is not statistically significant.

\section{Discussion}

Much research (e.g. Thaler, 1991; Kahneman and Knetsch, 1992), specifically designed to describe how decisions are made in a specific economic and financial setting, confirm that the subjective perception of what is deemed fair in an economic transaction is always biased by a reference framework (Kahneman and Tversky, 1984) affected by the magnitude of stimuli and the perceived subjective intensity of sensation (Fechner, 1860; Deco et al., 2007). This is the "framing effect" (Kahneman, 2003; Levin et al., 2002), whose influence on investors can cause a change from "risk averse" to "risk-seeking" behavior and vice versa (Kanheman and Tversky, 1979; Olsen, 1997a, b). The analysis presented in this paper, which has allowed us to observe Italian investors' risk-tolerance changes in the real world over 15 years, confirms the influence of the macroeconomic context on investors' decision-making process. Some of the obtained results are ambiguous, as for many other studies reported in the literature on this topic, but some interesting conclusions can be drawn.

Investors who live in the north of Italy are more risk tolerant than those who live in other areas. This behavior is in line with the GDP distinction between northern and centralsouthern Italy, such that northern Italians are more confident in risk-seeking when making their asset allocation choices. Hence, a sounder surrounding economic environment exerts a positive effect on risk-taking attitudes of investors: this is not surprising, since this underlying framework reduces the uncertainty in economic decision-making by the individuals.

Men turn out to be more risk tolerant than women. This is confirmed in every examined scenario and regardless of marital status. However, a reduction in risk appetite is observed over the crisis period (2009-2017). Therefore, male investors are not indifferent to the 
macroeconomic context: the advent of a crisis can flatten the differences between singles and married people.

The studies reported in the literature reach contradictory conclusions with reference to age. Our results allow us to argue that, in general, there is a negative relationship between age and risk appetite, although this relationship is not necessarily linear. However, in a positive economic scenario, (pre-crisis) age is not significant in determining the investors risk appetite. Indeed, after 2008, older people are less risk tolerant than younger ones. A more prudent risk attitude in a negative macroeconomic context is rational and supported by the status quo tendency. Kahneman and Tversky (2000) argue that investors decide by bearing in mind their status quo (i.e. their current level of well-being). In any situation where it might be altered, the decision procedure is adjusted (Tversky and Kahneman, 1981; Sonnemans et al., 1998) in order to keep it almost the same (Kahneman and Tversky, 1979). In this perspective, in a macroeconomic context of great uncertainty and with the possibility of incurring even significant financial losses, older people, who have a reduced survival prospect compared to younger ones, show less risk tolerance with the aim of protecting the level of wealth they have accumulated over time.

Investors' level of education does not seem to have an impact on risk tolerance, except in the pre-crisis period (2003-2008) when people with a higher level of education are more risk tolerant than people educated to a lower level. The positive macroeconomic context leads educated people to be more risk-seeking, while the context of uncertainty renders risk appetite insignificant. As previously stated in explaining the rationale behind $\mathrm{H} 3 \mathrm{a}$, during a financial downturn, more educated investors are expected to adjust their portfolio in a tactical way, reducing or increasing the riskiness of their investments according to the new information.

The analysis devoted to income-related covariates shows that retired people have dramatically reduced their risk-tolerance during the crisis; on the contrary, self-employed individuals have shown a greater risk attitude. Overall, these outcomes suggest that income matters in determining portfolio choices and this effect is likely to be magnified by the advent of severe economic and financial downturns.

Finally, our results identify a negative relationship between people's risk appetite and wealth, contrary to previous studies (e.g. Hallahan et al., 2004; Yao et al., 2004; Fan and Xiao, 2006). This outcome is interesting when coupled with the result obtained for the area dummy: it emerges as a picture where wealthier macroeconomic conditions promotes risk-seeking, while microeconomic (personal) attitudes may lead to an opposite behavior.

Overall, the results of our study provide guidance on investor behavior in the transition from normal market conditions to episodes of deep financial crisis. In this sense, the outcomes of the data analysis broadly confirm the conceptual framework and assumptions we made in Section 3.

The overall result is a comprehensive picture of the decision-making behavior of individuals in making investment choices during a period of severe economic and financial stress. In particular, gender, age and income level appear to be the drivers that most influence investors' risk-attitude. Education and marital status appear to be less explanatory impact.

\section{Conclusions}

Risk tolerance remains an extremely fascinating and stimulating research topic. Many demographic and socio-economic variables affect risk appetite in a dynamic mix. However, this study shows that the macroeconomic context is able to influence investors' risk tolerance significantly, thus modifying their portfolio asset allocations. In effect, risk tolerance is a topic in which psychological aspects merge and interact with financial opportunities and macroeconomic conditions. Under these assumptions, it must be noted that radical portfolio 
IJBM 38,5

changes due to risk-tolerance modification can generate an excess of transaction costs, leading to severe reductions in gains. Furthermore, the massive shift of capital from risky products to less risky ones can lead investors to incur significant opportunity losses and may involve sudden interruptions in financial planning strategies. In addition, some products may suffer in terms of lack of assets under management, liquidity problems, and biased price setting due to shocks in demand/supply with regard to financial products in the market.

Given the massive shifts in portfolio asset allocation observed in our sample, from a strategic point of view it may be useful for financial intermediaries to develop advanced asset management services to support their customers. In effect, the observed dynamics previously discussed in our study tend to undermine both the soundness of portfolio management over time and overall customer (and intermediary) satisfaction. In this sense, a closer relationship between private investors and their financial consultants should reduce the magnitude of portfolio changes over time and increase the speed of portfolio adjustments to the surrounding macroeconomic environment. Future research could focus on understanding how the presence of the financial advisor impacts on investors' risk tolerance. Furthermore, the impact of financial literacy programs on the choices made by investors in their asset allocation could be examined.

\section{Note}

1. Detailed figures on this topic are included in the "Surveys on Household Income and Wealth" undertaken since the 1960s by the Bank of Italy to gather data on the incomes and savings of Italian households, and available on the Bank of Italy's website (www.bancaditalia.it).

\section{References}

Bajtelsmit, V. and VanDerhei, J. (1997), "Risk aversion and pension investment choices", in Gordon, M., Mitchell, O. and Twinney, M., Positioning Pensions for the Twenty-First Century, University of Pennsylvania Press, Philadelphia, pp. 45-66.

Baker, H. and Haslem, J. (1974), "The impact of investor socioeconomic characteristics on risk and return preferences”, Journal of Business Research, Vol. 2 No. 4, pp. 469-476.

Bakshi, G. and Chen, Z. (1994), "Baby boom, population aging, and capital markets", Journal of Business, Vol. 67 No. 2, pp. 165-202.

Bateman, H., Islam, T., Louviere, J., Satchell, S. and Thorp, S. (2011), "Retirement investor risk tolerance in tranquil and crisis periods: experimental survey evidence", Journal of Behavioral Finance, Vol. 12 No. 4, pp. 201-218, doi: 10.1080/15427560.2011.620199.

Bell, N. and Bell, R. (1993), Adolescent Risk Taking, Sage, Newbery Park, CA.

Benartzi, S. and Thaler, R.H. (1995), "Myopic loss aversion and the equity premium puzzle", Quarterly Journal of Economics, Vol. 110 No. 1, pp. 73-92.

Bernasek, A. and Shwiff, S. (2001), "Gender, risk, and retirement”, Journal of Economic Issues, Vol. 35 No. 2, pp. 345-356, doi: 10.1080/00213624.2001.11506368.

Bernheim, B., Skinner, J. and Weinberg, S. (2001), "What accounts for the variation in retirement wealth among US households?”, American Economic Review, Vol. 91 No. 4, pp. 832-857, doi: 10. 1257/aer.91.4.832.

Boyd, W., Leonard, M. and White, C. (1994), "Customer preferences for financial services: an analysis", International Journal of Bank Marketing, Vol. 12 No. 1, pp. 9-15, doi: 10.1108/ 02652329410049562.

Burton, D. (1995), "Women and financial services: some directions for future research", International Journal of Bank Marketing, Vol. 13 No. 8, pp. 21-28, doi: 10.1108/02652329510098882. 
Chang, C., DeVaney, S. and Chiremba, S. (2004), "Determinants of subjective and objective risk tolerance", Journal of Personal Finance, Vol. 3 No. 3, pp. 53-67.

Chaulk, B., Johnson, P. and Bulcroft, R. (2003), "Effects of marriage and children on financial risk tolerance: a synthesis of family development and prospect theory", Journal of Family and Economic Issues, Vol. 24 No. 3, pp. 257-279, doi: 10.1023/A:1025495221519.

Cicchetti, C. and Dubin, J. (1994), "A microeconometric analysis of risk aversion and the decision to self-insure”, Journal of Political Economy, Vol. 102 No. 1, pp. 169-186.

Cohn, R., Lewellen, W., Lease, R. and Schlarbaum, G. (1975), "Individual investor risk aversion and investment portfolio composition”, The Journal of Finance, pp. 605-620, doi: 10.1111/j.1540-6261. 1975.tb01834.x.

Cutler, N. (1995), "Three myths of risk tolerance: what clients are not telling", Journal of Financial Service Professionals, Vol. 49 No. 1, pp. 33-38.

Dahlbäck, O. (1991), "Saving and risk taking", Journal of Economic Psychology, Vol. 12 No. 3, pp. 479-500, doi: 10.1016/0167-4870(91)90028-R.

Deco, G., Scarano, L. and Soto-Faraco, S. (2007), “Weber's law in decision making: integrating behavioral data in humans with a neurophysiological model", Journal of Neuroscience, Vol. 27 No. 42, pp. 11192-11200.

Donkers, B. and Van Soest, A. (1999), "Subjective measures of household preferences and financial decisions”, Journal of Economic Psychology, Vol. 20 No. 6, pp. 613-642, doi: 10.1016/S01674870(99)00027-6.

Embrey, L. and Fox, J. (1997), "Gender differences in the investment decision-making process", Financial Counseling and Planning, Vol. 8 No. 2, pp. 33-40.

Faff, R., Hallahan, T. and McKenzie, M. (2009), "Nonlinear linkages between financial risk tolerance and demographic characteristics", Applied Economics Letters, Vol. 16 No. 13, pp. 1329-1332, doi: 10.1080/13504850701381123.

Fan, J. and Xiao, J. (2006), "Cross-cultural differences in risk tolerance: a comparison between Chinese and Americans", Journal of Personal Finance, Vol. 5 No. 3, pp. 54-75.

Fechner, G.T. (1860), Elemente der Psychophysik, Breitkopf und Härtel, Leipzig.

Friedman, B. (1974), "Risk aversion and the consumer choice of health insurance option", The Review of Economics and Statistics, Vol. 56 No. 2, pp. 209-214, doi: 10.2307/1924441.

Gerrans, P., Faff, R. and Hartnett, N. (2015), "Individual financial risk tolerance and the global financial crisis", Accounting and Finance, Vol. 55 No. 1, pp. 165-185, doi: 10.1111/ acfi.12053.

Gilliam, J., Chatterjee, S. and Zhu, D. (2010), "Determinants of risk tolerance in the baby boomer cohort", Journal of Business and Economics Research, Vol. 8 No. 5, pp. 79-87.

Gollier, C. and Zeckhauser, R. (2002), "Horizon length and portfolio risk", Journal of Risk and Uncertainty, Vol. 24 No. 3, pp. 195-212, doi: 10.1023/A:1015697417916.

Grable, J. (2000), "Financial risk tolerance and additional factors that affect risk taking in everyday money matters", Journal of Business and Psychology, Vol. 14 No. 4, pp. 625-630, doi: 10.1023/A: 102299431.

Grable, J. and Joo, S. (1997), "Determinants of risk preference: implications for family and consumer science professionals", Family Economics and Resource Management Biennial, Vol. 2 No. 1, pp. 19-24.

Grable, J. and Joo, S. (2004), "Environmental and biophysical factors associated with financial risk tolerance", Journal of Financial Counseling and Planning, Vol. 15 No. 1, pp. 73-82.

Grable, J. and Lytton, R. (1999), “Assessing financial risk tolerance: do demographic, socioeconomic, and attitudinal factors work", Family Relations and Human Development/Family Economics and Resource Management Biennial, Vol. 3, pp. 80-88. 
IJBM 38,5

Grable, J., Lytton, R., O’neill, B., Joo, S. and Klock, D. (2006), "Risk tolerance, projection bias, vividness, and equity prices", Journal of Investing, Vol. 15 No. 2, pp. 68-74, doi: 10.3905/joi.2006.635632.

Graham, J.F., Stendardi, E.J., Myers, J.K. and Graham, M.J. (2002), "Gender differences in investment strategies: an information processing perspective", International Journal of Bank Marketing, Vol. 20 No. 1, pp. 17-26, doi: 10.1108/02652320210415953.

Guiso, L., Jappelli, T. and Terlizzese, D. (1996), "Income risk, borrowing constraints, and portfolio choice", The American Economic Review, Vol. 86 No. 1, pp. 158-172.

Gutter, M., Fox, J. and Montalto, C. (1999), "Racial differences in investor decision making”, Financial Services Review, Vol. 8 No. 3, pp. 149-162, doi: 10.1016/S1057-0810(99)00040-2.

Haliassos, M. and Bertaut, C. (1995), "Why do so few hold stocks?”, The Economic Journal, Vol. 105 No. 432, pp. 1110-1129, doi: 10.2307/2235407.

Hallahan, T., Faff, R. and McKenzie, M. (2004), "An empirical investigation of personal financial risk tolerance”, Financial Services Review, Vol. 13 No. 1, pp. 57-78.

Hanna, S., Gutter, M. and Fan, J. (2001), "A measure of risk tolerance based on economic theory", Journal of Financial Counseling and Planning, Vol. 12 No. 2, pp. 53-60.

Hari, J., Pirsch, E. and Rawitzer, H. (2018), "Women are scaredy-cats and men are conquerors?", Journal of Financial Services Marketing, Vol. 23, pp. 128-139, doi: 10.1057/s41264-018-0045-x.

Hariharan, G., Chapman, K.S. and Domian, D. (2000), "Risk tolerance and asset allocation for investors nearing retirement”, Financial Services Review, Vol. 9 No. 2, pp. 159-170, doi: 10.1016/S10570810(00)00063-9.

Hartog, J., Ferrer-i-Carbonell, A. and Jonker, N. (2002), "Linking measured risk aversion to individual characteristics”, Kyklos, Vol. 55 No. 1, pp. 3-26, doi: 10.1111/1467-6435.00175.

Hawley, C. and Fujii, E. (1993-1994), "An empirical analysis of preferences for financial risk: further evidence on the Friedman-Savage model”, Journal of Post Keynesian Economics, Vol. 16 No. 2, pp. 197-204, doi: 10.1080/01603477.1993.11489978.

Hinz, R., McCarthy, D. and Turner, J. (1997), "Are women conservative investors? Gender differences in participant-directed pension investments", in Gordon, M., Mitchell, O. and Twinney, M., Positioning Pensions for the Twenty-First Century, University of Pennsylvania Press, Philadelphia, pp. 91-103.

Hoffmann, A., Post, T. and Pennings, J. (2013), "Individual investor perceptions and behavior during the financial crisis", Journal of Banking and Finance, Vol. 37 No. 1, pp. 60-74, doi: 10.1016/j. jbankfin.2012.08.007.

Horvath, P. and Zuckerman, M. (1993), "Sensation seeking, risk appraisal, and risky behavior", Personality and Individual Differences, Vol. 14 No. 1, pp. 41-52, doi: 10.1016/0191-8869(93) 90173-Z.

Huston, S., Chang, Y. and Metzen, E. (1997), "Economic, demographic and attitudinal characteristics of American households by household type", Family Economics and Resource Management Biennial, Vol. 2 No. 9, p. 18.

Irwin, C. (1993), “Adolescence and risk taking: how are they related?”, in Bell, N. and Bell, R., Adolescent Risk Taking, Sage, Newbury Park, CA.

Jamal, A. and Naser, K. (2002), "Customer satisfaction and retail banking: an assessment of some of the key antecedents of customer satisfaction in retail banking", International Journal of Bank Marketing, Vol. 20 No. 4, pp. 146-160, doi: 10.1108/02652320210432936.

Jianakoplos, N. and Bernasek, A. (1998), “Are women more risk averse?”, Economic Inquiry, Vol. 36 No. 4, pp. 620-630, doi: 10.1111/j.1465-7295.1998.tb01740.x.

Kahneman, D. (2003), "Maps of bounded rationality: psychology for behavioral economics", The American Economic Review, Vol. 93 No. 5, pp. 1449-1475.

Kahneman, D. and Knetsch, J. (1992), "Valuing public goods: the purchase of moral satisfaction", Journal of Environmental Economics and Management, Vol. 22 No. 1, pp. 57-70. 
Kahneman, D. and Riepe, M. (1998), "Aspects of investor psychology: beliefs preferences and biases in investment advisors should know about", Journal of Portfolio Management, Vol. 24, pp. 52-65.

Kahneman, D. and Tversky, A. (1979), "Prospect theory: an analysis of decision under risk", Econometrica, Vol. 47 No. 2, pp. 263-292.

Kahneman, D. and Tversky, A. (1984), "Choices, values, and frames”, American Psychologist, Vol. 39 No. 4, pp. 341-350.

Kahneman, D. and Tversky, A. (2000), Choices, Values, and Frames, Russell Sage Foundation, New York, Cambridge.

Kennickell, A., Starr-McCluer, M. and Sunden, A. (1997), "Saving and financial planning: some findings from a focus group", Journal of Financial Counseling and Planning, Vol. 8 No. 1, pp. 1-8.

Levesque, T. and McDougall, G.H. (1996), "Determinants of customer satisfaction in retail banking", International Journal of Bank Marketing, Vol. 14 No. 7, pp. 12-20, doi: 10.1108/ 02652329610151340 .

Levin, I., Gaeth, G., Schreiber, J. and Lauriola, M. (2002), "A new look at framing effects: distribution of effect sizes, individual differences, and independence of types of effects", Organizational Behavior and Human Decision Processes, Vol. 88 No. 1, pp. 411-414, doi: 10.1006/obhd. 2001.2983.

Masters, R. (1989), "Study examines investors's risk-taking propensities", Journal of Financial Planning, Vol. 2 No. 3, pp. 151-155.

McInish, T. (1982), "Individual investors and risk-taking", Journal of Economic Psychology, Vol. 2 No. 2, pp. 125-136, doi: 10.1016/0167-4870(82)90030-7.

Meyer, H., Walker, W. and Litwin, G. (1961), "Motive patterns and risk preferences associated with entrepreneurship", Journal of Abnormal and Social Psychology, Vol. 63 No. 3, pp. 570-574, doi: 10.1037/h0043698.

Morin, R. and Suarez, A. (1983), "Risk aversion revisited", The Journal of Finance, Vol. 38 No. 4, pp. 1201-1216, doi: 10.1111/j.1540-6261.1983.tb02291.x.

Morse, W. (1998), "Risk taking in personal investments", Journal of Business and Psychology, Vol. 13 No. 2, pp. 281-288, doi: 10.1023/A:102291522.

Olsen, R. (1997a), “Investment risk: the experts' perspective”, Financial Analysts Journal, Vol. 53 No. 2, pp. 62-66, doi: 10.2469/faj.v53.n2.2073.

Olsen, R. (1997b), "Prospect theory as an explanation of risky choice by professional investors: some evidence”, Review of Financial Economics, Vol. 6 No. 2, pp. 225-232, doi: 10.1016/S1058-3300(97) 90008-2.

Pålsson, A. (1996), "Does the degree of relative risk aversion vary with household characteristics?", Journal of Economic Psychology, Vol. 17 No. 6, pp. 771-787, doi: 10.1016/S0167-4870(96) 00039-6.

Powell, M. and Ansic, D. (1997), "Gender differences in risk behaviour in financial decision-making: an experimental analysis”, Journal of Economic Psychology, Vol. 18 No. 6, pp. 605-628, doi: 10.1016/ S0167-4870(97)00026-3.

Quattlebaum, O. (1988), "Loss aversion: the key to determining individual risk", Journal of Financial Planning, Vol. 1 No. 2, pp. 66-69.

Riley Jr, W. and Chow, K. (1992), “Asset allocation and individual risk aversion”, Financial Analysts Journal, Vol. 48 No. 6, pp. 32-37, doi: 10.2469/faj.v48.n6.32.

Roszkowski, M., Snelbecker, G. and Leimberg, S. (1993), "Risk tolerance and risk aversion", in Leimberg, S., Satinsky, M., LeClair, R. and Doyle, R., The Tools and Techniques of Financial Planning, 4th ed., National Underwriter, Cincinnati, OH, pp. 213-225.

Schooley, D. and Worden, D. (1996), "Risk aversion measures: comparing attitudes and asset allocation”, Financial Services Review, Vol. 5 No. 2, pp. 87-99, doi: 10.1016/S1057-0810(96) 90003-7. 
IJBM 38,5

Schooley, D. and Worden, D. (2016), "Perceived and realized risk tolerance: changes during the 2008 financial crisis", Journal of Financial Counseling and Planning, Vol. 27 No. 2, pp. 265-276, doi: 10. 1891/1052-3073.27.2.265.

Shaw, K. (1996), "An empirical analysis of risk aversion and income growth", Journal of Labor Economics, Vol. 14 No. 4, pp. 626-653, doi: 10.1086/209825.

Shelbecker, G. and Roszkowski, M. (1993), "Risk tolerance and risk aversion", in Leimberg, S., Satinsky, M., LeClair, R. and Doyle, R., The Tools and Techniques of Financial Planning, 4th ed., National Underwriter, Cincinnati, OH, pp. 213-225.

Sonnemans, J., Schram, A. and Offerman, T. (1998), "Public good provision and public bad prevention: the effect of framing", Journal of Economic Behavior and Organization, Vol. 34 No. 1, pp. 143-161, doi: 10.1016/S0167-2681(97)00042-5.

Sunden, A. and Surette, B. (1998), "Gender differences in the allocation of assets in retirement savings plans", The American Economic Review, Vol. 88 No. 2, pp. 207-211.

Sung, J. and Hanna, S. (1996), "Factors related to risk tolerance", Financial Counseling and Planning, Vol. 7, pp. 11-20.

Thaler, R. (1991), Quasi Rational Economics, Russell Sage Foundation, New York, NY.

Tigges, P., Riegert, A., Jonitz, L., Brengelmann, J. and Engel, R. (2000), "Risk behavior of East and West Germans in handling personal finances", The Journal of Psychology and Financial Markets, Vol. 1 No. 2, pp. 127-134, doi: 10.1207/S15327760JPFM0102_4.

Trone, D., Allbright, W. and Taylor, P. (1996), The Management of Investment Decisions, McGraw Hill Professional.

Tversky, A. and Kahneman, D. (1981), "The framing of decisions and the psychology of choice", Science, Vol. 211 No. 4481, pp. 453-458, doi: 10.1126/science.7455683.

Wallach, M. and Kogan, N. (1961), "Aspects of judgment and decision making: interrelationships and changes with age”, Behavioral Science, Vol. 6 No. 1, pp. 23-36, doi: 10.1002/bs.3830060104.

Wang, H. and Hanna, S. (1997), "Does risk tolerance decrease with age?", Financial Counseling and Planning, Vol. 8 No. 2, pp. 27-31, doi: 10.2139/ssrn.95489.

Wong, A. and Carducci, B. (1991), "Sensation seeking and financial risk taking in everyday money matters", Journal of Business and Psychology, Vol. 5 No. 4, pp. 525-530, doi: 10.1007/BF01014500.

Xiao, J. and Anderson, J. (1997), "Hierarchical financial needs reflected by household financial asset shares", Journal of Family and Economic Issues, Vol. 18 No. 4, pp. 333-335.

Xiao, J., Alhabeeb, M., Hong, G. and Haynes, G.W. (2001), "Attitude toward Risk and risk-taking behavior of business-owning families", Journal of Consumer Affairs, Vol. 35 No. 2, pp. 307-325, doi: 10.1111/j.1745-6606.2001.tb00116.x.

Yao, R., Hanna, S. and Lindamood, S. (2004), “Changes in financial risk tolerance, 1983-2001", Financial Services Review, Vol. 13 No. 4, pp. 249-266.

Yook, K. and Everett, R. (2003), “Assessing risk tolerance: questioning the questionnaire method", Journal of Financial Planning, Vol. 16 No. 8, pp. 48-55.

Zhong, L. and Xiao, J. (1995), "Determinants of family bond and stock holdings", Financial Counseling and Planning, Vol. 6, pp. 107-114.

Zuckerman, M. (1979), Sensation Seeking: Beyond the Optimal Level of Arousal, Erlbaum Associates, New York, NY.

\section{Further reading}

Carducci, B. and Wong, A. (1998), "Type A and risk taking in everyday money matters", Journal of Business and Psychology, Vol. 12 No. 3, pp. 355-359, doi: 10.1023/A:1025031614989. 
About the authors

Andrea Lippi is Researcher of Economic of Financial Intermediaries at the Università Cattolica del Scaro Cuore, Piacenza site. He wrote papers about behavioral finance, private banking and banking system in general. Andrea Lippi is the corresponding author and can be contacted at: andrea.lippi@unicatt.it

Simone Rossi is Researcher of Economic of Financial Intermediaries at the Università Cattolica del Scaro Cuore, Piacenza site. He wrote papers about banking system profitability and banking system structure.

Italian
investors' risk
appetite

1213

For instructions on how to order reprints of this article, please visit our website:

www.emeraldgrouppublishing.com/licensing/reprints.htm

Or contact us for further details: permissions@emeraldinsight.com 